\title{
O HOMEM E A TERRA: NATUREZA DA REALIDADE GEOGRÁFICA
}

\author{
(Eric Dardel, 2011)
}

David Emanuel Madeira Davim

\section{Introdução}

Tão importante quanto revisitar os clássicos esquecidos de uma disciplina, ou campo de conhecimento, é explorar as obras que ainda não foram totalmente resgatadas do desconhecido. Assim alguns estudiosos entendem a importância do livro O Homem e a Terra: Natureza da Realidade Geográfica escrito pelo geógrafo francês Éric Dardel, publicado, originalmente, em 1952 e traduzido para o português, em 2011. Um livro muito esperado por seguimentos da comunidade geográfica brasileira, sobretudo pelos estudantes e pesquisadores afeiçoados à vertente humanista e cultural.

Como bem apresentado por Werther Holzer (2011), O Homem e a Terra não se trata apenas de uma interpretação geográfica densa e rica, na articulação de perspectivas filosóficas e literárias, mas o tratado de geografia fenomenológica mais bem elaborado até o momento. Ao decorrer de suas páginas é possível desfrutar a maestria de como um geógrafo pode apropriar-se de elementos fundamentais de reflexões espaciais e filosóficas presentes nos pensamentos de mestres como Heidegger, Hölderlin, Bachelard, Goethe, entre outros.

O livro se divide em dois capítulos, sendo que o primeiro, O espaço geográfico, traz todo o esforço geopoético e epistemológico do autor, com destaque para o seu conceito de geograficidade. No segundo, A História da Geografia, Dardel narrar uma surpreendente trajetória da consciência geográfica, em contextos temporais distintos, desde as sociedades antigas, finalizando em sua análise crítica sobre a Geografia científica do século XIX.

\section{Capitulo 1 - 0 espaço geográfico}

No iniciar de sua obra, Dardel nos convida a pensar sobre a Geografia a partir de um dos últimos episódios de sua perspectiva histórica, isto é, o contexto dos séculos XVIII e XIX. Neste período, a Geografia se estabelece enquanto ciência, reflexo do amadurecimento do espírito moderno que conquista a maior parte da cena intelectual do ocidente. Na leitura de Dardel (2011), a modernidade, inaugurada com as grandes expedições ultramarinas, se fez um rompimento com o escasso interesse pela terra, tão marcante no pensamento medieval. A modernidade, em seu frescor, se apresentaria como o retorno à proximidade entre homem e terra, tão exuberante na antiguidade, etapas bem exploradas no segundo capítulo do livro.

Todavia, a modernidade caminharia passo a passo ao abandono daquilo que Dardel (2011, p. 1) denomina de "vontade intrépida de correr, explorar e descobrir" o mundo. Em seu lugar toma força uma "vontade de medir, calcular e analisar" a terra. Vontade esta que se consolida na Geografia objetiva e positivista de gabinete que, no contexto histórico, vivido pelo autor, ainda estava vigente e predominante.

A Geografia científica do século XIX abandonou a interpretação ontológica da terra, por acreditar que não haveria mais nenhum espaço no mundo a se descobri e conhecer. A disciplina então passa a assumir uma leitura essencialmente geométrica e analítica, leitura esta fundamentada nas perspectivas fiscalistas, inspiradas em princípios newtonianos de espaço abstrato, homogêneo e vazio de conteúdo. Tal perspectiva serviria ao domínio mecanicista e administrativo do mundo.

Em um tom crítico Dardel (2011), propõe como alternativa de renovação à ciência, o retorno a uma relação primitiva, de íntima proximidade entre homem e terra, uma Geografia em ato, por um encontro caracterizado pelo jogo (luta) de ações concretas, que também proporcionam criações subjetivas pelo interesse de conquista e descoberta, assim como pela surpresa diante dos fenômenos geográficos e cotidianos. É a esta relação concreta e interessada entre homem e terra que Dardel destaca como alicerce daquilo que denominou por geograficidade, conceito fundamental de seu pensamento. Para Dardel a Geografia traz em sua etimologia grega o sentido originário de uma ontologia hermenêutica, ou seja, um ato fundante de descrição, decifração e esclarecimento sobre as formas, desenhos e recortes das paisagens da terra. Seria a terra, portanto, uma espécie de texto composto por signos que incita e se apresenta à interpreção do geógrafo. 
Para que tal interpretação se estabeleça, Dardel recorre ao uso da fenomenologia enquanto método ontológico de apreensão da efetividade concreta e circundante. A experiência existencial ocorrida em meio a uma adesão contigua (ou cumplicidade) entre homem e terra é o que oferece à sensibilidade humana condições fundamentais de apreensão do mundo, em meio à existência.

A terra para Derdel (2011), semelhante às interpretações filosóficas da antiguidade e românticas do século XVIII, é uma materialidade dotada de vida, potência e dinamismo próprio. Deste modo, a terra, assim como o espaço geográfico, é a própria matéria, a substância gasosa que compõe os céus (espaço aéreo); as águas que formam os oceanos os rios e lagos, assim como o gelo que caracteriza as formações glaciais (espaço aquático); a areia que se espraia por costas e desertos, as rochas que se consolidam em serras e montanhas, o solo e a vegetação que compõe campos e florestas (espaço telúrico); o concreto, o aço e o vidro que sustentam as cidades e suas infraestruturas (espaço construído). Trata-se de um espaço vivo, móvel e que nos afeta como em uma espécie de combate, oferecendo acolhimento, obstáculo, estímulo e resistência à liberdade de construir e habitar do humano.

Ao oferecer estímulo e resistência, a matéria, que se configura em espaço geográfico, exige da experiência e sensibilidade humana o intuir de qualidades, a exemplo dos valores de alto, sólido, amplo, pastoso, pesado, espesso, molhado, quente, distante, entre outros tantos, que pensados acabem por fundar conceitos, noções e medidas humanas de conhecimento. Neste sentido a perspectiva de espaço geográfico assume caráter antropocêntrico de interpretação, isto é, a realidade só é geográfica para o ser humano, seus inúmeros interesses e o reconhecimento de si mesmo. Nesta visão, o homem, portanto, é o único capaz de estabelecer diálogo com a terra, compreendê-la e respondê-la.

A presença dessa vitalidade do espaço material se revela diante do homem como uma espécie de linguagem, uma forma comunicativa, que Dardel (2011, p. 6) sinaliza como uma um "apelo" ou "confidência" que a sensibilidade pode captar e traduzir. Esse apelo da terra brota de suas particularidades materiais, sejam elas de origem natural ou artificial. Um apelo que se manifesta como um verdadeiro jogo de ocultamento e revelação (sombra $\mathrm{x}$ luz) sobre sentidos e essências do mundo circundante. Um campo de forças em luta que atinge o homem, tanto como oportunidade, quanto como obstáculo para suas intenções e presença, seu destruir, engendrar e ordenar sobre o solo.

O desafio fenomenológico e hermenêutico que fundamenta a geograficidade derdeliana exige do geógrafo o exercício de uma liberdade espiritual e subjetiva capaz de transmutar a realidade concreta, proporcionada pelo sentir a terra, em uma irrealidade imaginária, onírica e fantástica, criadora de uma perspectiva de mundo pensado. Essa irrealidade, fruto da criação do geógrafo, não se configura como algo avesso ao real, mais uma superação deste, um ir-além-do-real. Como nos dizeres de Dardel (2011, p. 34), não se trata aqui de estabelecer uma "Geografia patética" de "pura fantasia”, mas tingir, afetivamente, um espaço primitivo, que salta da concretude dos lugares para o corpo e, por consequência mobiliza, nossos desejos, vontades e pensamentos. Esta subjetividade, convertida em fala e em texto, exige também que o geógrafo faça uso de um estilo poético-literário para então apresentar sua mensagem (interpretação), ou seja, desmaterializar a expressividade (sua paisagem) concreta da terra em nomeação, palavras, ou, como prefere Dardel (2011, p. 13), em um "vocabulário".

Essa linguagem geográfica veicula em sua sonoridade ritmada uma coloração afetiva que, em sua ressonância, desperta nos seres humanos, um ato de consciência, sentimentos e afetos ligados intimamente à imagem e memória de lugares e regiões experienciadas e imaginadas. Imagens e realidades geográficas que o autor supõe já existir dentro de cada um de nós. Para o autor de $O$ Homem e a Terra, o espaço primitivo, assim como sua interpretação poética sobre a realidade geográfica, supera a análise objetiva da ciência convencional por sua maior proximidade e fidelidade ao apelo terrestre. A poesia neste sentido se faz mais fácil, transparente, interessante e surpreendente para a compreensão e a imaginação humana, dando às nuanças da terra mais vivacidade, cor, vibração e intensidade expressiva.

Essa Geografia poética, ou geograficidade, se faz, a princípio, um modo de ser e, consequentemente, um modo fenomenológico e hermenêutico de se conhecer a realidade. No campo do saber ela se configura não só como um enfrentamento aos limites impostos pela ciência moderna, mas também como um resgate aos alicerces de uma Geografia existencial, ontológica, mítica e heroica, que se fez frutífera nos tempos anteriores. Uma Geografia que tem o lugar como base e fundamento para o desdobrar de uma contiguidade circunstancial e existencial que a paisagem estabelece entre homem e terra. Uma geografia que enxerga na paisagem um horizonte e um impulso de possibilidades para a fundação de mundos caracterizados por espaços únicos e diferenciados.

\section{Capitulo 2 - A História da Geografia}

No segundo capítulo de O Homem e a Terra, Dardel nos propõe uma formidável e distinta perspectiva histórica sobre a Geografia. O próprio autor salienta que sua narrativa não pode ser confundida com uma cronologia dos descobrimentos e mapeamentos sobre a terra, muito menos com uma periodização sobre a trajetória do desenvolvimento científico-institucional da Geografia. A História da Geografia que Dardel (2011) nos conta é, na verdade, o caminho do despertar e do desdobrar de uma consciência geográfica, estimulada pela relação direta do 
homem com a expressividade fisionômica da terra, sua realidade circundante e cotidiana.

Tal trajetória, apresentada por Dardel, é, portanto, a História da própria geograficidade. O caminho temporal de um modo de ser (existência) pautado na interpretação, que transita entre homem e terra, que por sua vez, estabelece como horizonte, base e esclarecimento para a fundação de diferentes concepções geográficas de mundo. Entre essas Dardel destaca: a Geografia (interpretação) mítica, profética e heroica, assim como a Geografia das velas desfraldadas e, por fim, a Geografia científica do século XIX.

\section{Geografia Mítica}

A geografia dos ditos "primitivos", das sociedades tradicionais (tribais) que, segundo o autor também era vigente na antiguidade e no medievo. Essa é a leitura fundamentada em um universo mágico, um mundo visto por uma perspectiva mítica. Nessa atmosfera interpretativa, a terra, em sua composição total (terra, ar, água), é dotada de poderes naturais e sobrenaturais. Ela é a origem, o solo, o útero, a mãe de tudo e de todos os seres. Fonte de fertilidade, nutriente, chão pátrio, elo parental da relação vivida, existencial e afetiva junto ao homem. A terra proporciona a coletividade humana (clã), possibilitando a vida em comunidade, trabalho, trocas, parcerias e conflitos.

A terra, na concepção mítica, não é só origem, mas a presença em constante manifestação e renovação. As expressividades de seu tempo e de seus ciclos naturais de eterno retorno reverberam sobre os ritmos e ordens da vida humana, estabelecendo as interpretações míticas e as performances ritualísticas que validam e organizam a realidade geográfica de cada cultura. A partir desses mitos e ritos a terra passa a ser vista pelos homens como digna de sagradas e profanas qualidades. Aspectos sobrenaturais que vão além de sua pura materialidade, base fundamental para o surgimento das primeiras religiões.

\section{Geografia (interpretação) Profética}

Segundo a leitura de Dardel (2011), foi neste contexto que a relação entre homem e terra sofreu sua primeira e profunda perturbação. Com a abertura para o ritualismo e a religião, concedida pela própria geografia mítica, seguimentos da sociedade passam a recriar valores em meio a inquietações metafísicas, dando origem às perspectivas proféticas. Dentre as mais delineadas entre elas, o profetismo bíblico, de orientação monoteísta, que destitui a terra de seu caráter originário, fonte sagrada da existência, dotada de alma, poder próprio e presença, para ser rebaixada à condição de mera substância passiva, obra e desígnio de um criador, meio para o fim e uma história arquitetada por um Deus tido por verdadeiro.
O homem, gestado do sopro deste Deus, que (segundo as liturgias) projetou em nós sua própria imagem, passa a assumir posição hierárquica (elevada) diante da terra. Nessa perspectiva a terra não passa de uma materialidade subsistente, temporária, limitada, que manifesta o poder de um Deus infinito e eterno e se faz dom, assim como testemunho de seu poder. Desacralizada a terra torna-se o oposto do céu (morada de Deus), condenada e profanada a uma falsa divindade, solo da heresia, paganismo, maldade e supertição, destinada a servir o homem como recurso de valor utilitário.

\section{Geografia Heroica}

Também interpratada como a geografia aventureira, exploratória e lendária. Versadas nas proezas das narrativas de viagens. Essa geografia é tida por Dardel (2011) enquanto aquela que, ao mesmo tempo, se aproxima e se afasta da concepção mítica sobre a efetividade. Aproxima-se, pois ainda mantém sua relação de fidelidade à terra, impregnada com as concepções míticas e mágicas das comunidades antigas e tradicionais. Afasta-se, pois desafia a dominação coletiva do clã, em detrimento da exaltação da figura do herói, aquele que enfrenta sozinho as potencialidades dos deuses e da natureza. Tal exaltação proporcionou o domínio da figura masculina, nobre e aristocrática, isto é, o patriarca monárquico.

A geografia heroica também se fez alicerce para uma primeira e superficial consciência histórica, que se desprende do mito totêmico dos clãs e estabelece, por meio de sua poesia épica, interpretações cosmológicas sobre o mundo exterior. Diferentemente da perspectiva profética, a terra para a geografia heroica retorna a manifestar suas potencialidades próprias, porém, tendo projetada sobre si a imagem do panteão divino que, representado pela natureza, impõe à liberdade humana desafios e obstáculos sobre suas conquistas aos espaços.

\section{Geografia das Velas Desfraldadas}

Esta apresenta uma linha tênue que, de certa forma, a diferencia da geografia heroica. Dardel (2011, p. 78), em alguns momentos, expressa que o contexto das grandes navegações pode ser confundido, até mesmo servir de "capítulo", ou continuidade às aventuras épicas da primeira revolução da consciência geográfica. A geografia das grandes explorações e expedições ultramarinas é avessa ao trabalho de gabinete e laboratório, pois nela ainda pulsa uma vontade de poder que alicia o homem a uma inquietação espacial. Vocação em descobrir, conhecer, conquistar e fundar mundos, que consegue ir além dos interesses políticos e econômicos. Vontade que se manteve rebelde aos imperativos da metafísica e da moral profética, assim como desconhecedora das supostas leis invariáveis da natureza. 
Para a geografia exploratória, ainda cabe à terra interpretações poéticas, épicas e maravilhadas, advindas da experiência afetiva. Pois neste contexto, a natureza ainda é animada por forças mágicas e sobrenaturais. Suas conquistas heroicas, movidas por coragem, dificultadas por terríveis riscos e fins trágicos, levou a humanidade a amadurecer sua consciência geográfica, alargar suas dimensões espaciais e enriquecer de imagens a nossa subjetividade e conhecimento sobre outros mundos e povos.

\section{Geografia Científica}

A Geografia que atrai o tom crítico da leitura de Dardel, por ser despossuída de maior geograficidade. As perspectivas que a consolidaram tiveram suas raízes, não só na maturidade moderna do século XVIII, mas em toda a trajetória humana, desde as motivações mercantis das antigas rotas comerciais, passando pelas concepções religiosas de infinito, da idade média, até os registros coletados em meio às aventuras ultramarinas. A Geografia científica é a Geografia dos mapas e inventários dos fatos geográficos, matéria prima, conteúdo descritivo para a confirmação rigorosa de hipóteses e leis invariáveis, que fundamentaram a Matemática e a Física das explicações mecanicistas e absolutas sobre a realidade.

Para exercer essa Geografia objetiva o geógrafo deve abandonar seu diálogo afetivo com a terra, além de sua perspectiva poética, mítica e lendária. O investigador deve deixar em repouso seu gosto e alegria pelo risco das aventuras e inquietudes geográficas, enfraquecer sua vontade de correr, descobrir e conquistar mundos. Essa é a Geografia dos laboratórios, institutos, organismos e revistas de pesquisas, que buscam, com todo vontade de verdade, um conhecimento válido, rigoroso e verossímil sobre a terra enquanto mero objeto de seu interesse empreendedor.

\section{Conclusão}

Dardel conclui o último capítulo, referente à História da Geografia, nos alertando sobre o alto preço pelo uso, feito em sua época, de uma Geografia puramente objetiva. O conhecimento do contexto moderno (ocidental), por meio de suas representações, cálculos e medidas, municiou, não só a ciência, mas o conjunto dos empreendimentos econômicos com as técnicas e os instrumentos necessários para fazer do homem, não só o senhor da natureza, como também o detentor da verdade. E por meio destes poderes e possibilidades a humanidade pode se apartar da natureza, assim como também foi capaz de ameaçar a saúde da terra e a sã convivência entre povos e culturas.

Mesmo esboçando, em meados do século XX, um cenário preocupante e destrutivo na relação entre homem e terra, Dardel (2011) é capaz de enxergar contradições que nos abrem caminhos para um retorno a uma geografia mais humana. Ao mesmo tempo em que o homem traça em seu destino um distanciamento profundo em relação à natureza, o mesmo criou tímidas e esporádicas possibilidades de se evadir dos ambientes urbanos e artificiais, estabelecendo assim um reencontro com a terra e consigo mesmo. Para Dardel o homem moderno, assim como a ciência institucional, precisam se convencer que o poder de sua atual e hegemônica objetividade surgiu de uma subjetividade gestada na relação vivida, próxima e íntima com a terra. Essa relação precisa ser resgatada e fortalecida, assim como é preciso refundar a geograficidade que marcava os períodos heroicos e desbravadores.

\section{Referências}

Dardel, É. (2011). O Homem e a Terra: natureza da realidade geográfica. (Trad. Werther Holzer) São Paulo: Editora Perspectiva.

David Emanuel Madeira Davim - Possui graduação em Geografia pela Faculdade de Ciências e Tecnologia, (FCT-UNESP) Campus de Presidente Prudente-SP; é Mestrando do curso de Geografia do Instituto de Geociências (IG) da UNICAMP, tendo por linha de investigação: epistemologia em Geografia, Geografia Humanista e Fenomenológica e Filosofia Contemporânea (destaque para a proposta nietzschiana e heideggeriana de pensamento). Docente da Universidade Estadual de Campinas. E-mail: davidavim@hotmail.com 